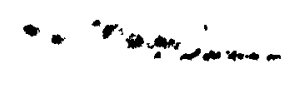

D.P. $-1,396$

\title{
NEPTUNIUM AND PLUTONIUM \\ VALENCE ADJUSTMENT IN ENRICHED URANIUM PROCESSING
}

\section{C. THOMPSON}

G. A. BURNEY

M. L. HYDER

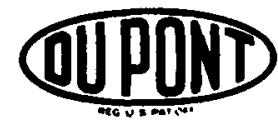

SAVANNAH RIVER LABORATORY

AIKEN, SOUTH CAROLINA 29801

PREPARED FOR THE U.S. ENERGY RESEARCH AND DEVELOPMENT AOMINISTRATION UNDER CONTRACT AT(O7 2) 1 


\section{NOTICE}

This report was prepared as an sccount of work sponsored by the United States Government. Neither the United States nor the United States Energy Research and Development Administration, nor any of their contractors, subcontractors, or their employees, makes any warrenty. express or implied, or assumes any legal lisbility or responsibility for the sccuracy, completeness or usofulness of any information, apparatus, product or process disclosed, or represents that its use would not infringe privately owned rights.

Printed in the United States of America

Available from

National Technical Information Sarvice

U. S. Department of Commerce 5285 Port Royal Road Springfield, Virginia 22161

Price: Printed Copy \$5.00; Microfiche \$2.25 


\section{DISCLAIMER}

This report was prepared as an account of work sponsored by an agency of the United States Government. Neither the United States Government nor any agency Thereof, nor any of their employees, makes any warranty, express or implied, or assumes any legal liability or responsibility for the accuracy, completeness, or usefulness of any information, apparatus, product, or process disclosed, or represents that its use would not infringe privately owned rights. Reference herein to any specific commercial product, process, or service by trade name, trademark, manufacturer, or otherwise does not necessarily constitute or imply its endorsement, recommendation, or favoring by the United States Government or any agency thereof. The views and opinions of authors expressed herein do not necessarily state or reflect those of the United States Government or any agency thereof. 


\section{DISCLAIMER}

Portions of this document may be illegible in electronic image products. Images are produced from the best available original document. 


\section{NEPTUNIUM AND PLUTONIUM \\ VALENCE ADJUSTMENT IN ENRICHED URANIUM PROCESSING}

by

M. C. THOMPSON

G. A. BURNEY

M. L. HYDER

Approved by

W. H. Hale, Jr., Research Manager

Separations Chemistry Division

Publication Date: March 1976

This report watice

This report was prepared as an account of work sponsored by the United States Government Nerther Research and Development Admunistration, nor any of therr employess, nor any of therr, contractors. subcontractors, or thent empioyees, makes any watraniy, express or implied, or assumes any legal fiabuly or responsbubty for the accuracy, completeness or usefulnes of any information, apparatus, product or process disclosed, or represents that its use would not infringe privately owned nghts

E I DU PONT DE NEMOURS AND COMPANY SAVANNAH RIVER LABORATORY AIKEN, SOUTH CAROLINA 29801

PREPARED FOR THE U.S. ENERGY RESEARCH AND DEVELOPMENT AOMINISTRATION UNDER CONTRACT AT 10721 
In initial operation of a new flowsheet for recovery of highly irradiated enriched uranium by solvent extraction with 7.5 vol \% tri-n-butyl phosphate, valence adjustment of plutonium and neptunium with ferrous sulfamate was ineffective; plutonium was not rejected as desired, and neptunium was partially lost to waste. Laboratory studies demonstrated that ferrous sulfamate, added to both the aqueous feed solution and the aqueous scrub stream in the first stage (1AS), was largely destroyed during the relatively long time between preparation and use of these solutions. Radiolysis destroyed the ferrous ion in the feed in a few hours, and nitric acid oxidized much of the ferrous ion in the scrub solution. To achieve the desired neptunium-plutonium separation in plant operation, the process flowsheet was modified as follows: ferrous sulfamate is added to the lAS stream immediately before it enters the mixer-settler, and ferrous sulfamate is not added to the feed solution where it would be destroyed by radiolysis. 


\section{CONTENTS}

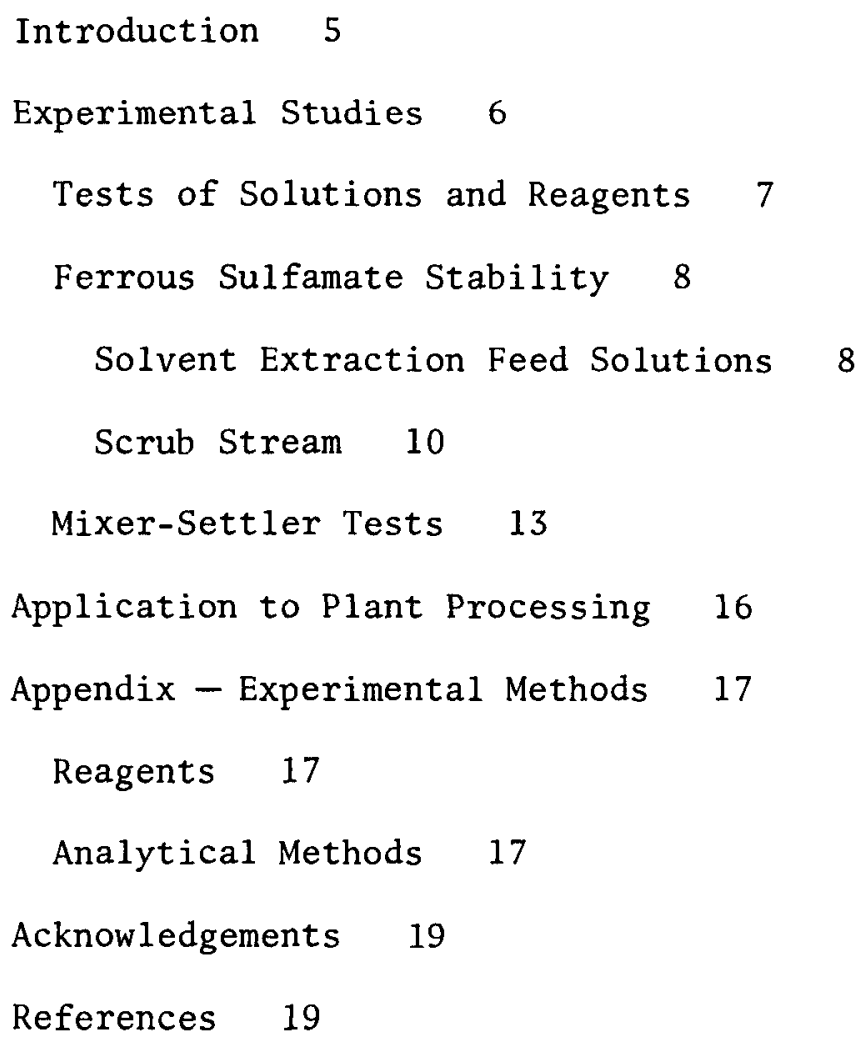




\section{LIST OF FIGURES}

1 Flowsheet for Processing Enriched Uranium 6

2 Electrochemical Potential as a Function of Added Ferrous Sulfamate $(0.02 \mathrm{M})$ in Solvent Extraction Feed 8

3 Potential, $\mathrm{Np}^{4^{+}}$, and $\mathrm{Pu}^{4^{+}}$as a Function of Time after Addition of $0.02 \mathrm{M}$ Ferrous Sulfamate in Short-Cooled Dissolver Solution 9

\section{LIST OF TABLES}

1 Analyses of Process Solutions 7

2 Rate Constants for $\mathrm{Fe}^{2+}$ Oxidation 11

3 Mixer-Settler Tests of Ferrous Sulfamate Stability 12

4 Reaction of Nitrite with Ferrous Sulfamate 12

$5 \quad$ Miniature Mixer-Settler Tests 13 


\section{NEPTUNIUM AND PLUTONIUM VALENCE ADJUSTMENT IN ENRICHED URANIUM PROCESSING}

\section{INTRODUCTION}

A modified solvent extraction process for recovering uranium and neptunium from irradiated enriched uranium fuels was developed and tested in Savannah River Plant (SRP) operation in 1973 and 1974. Operation of this process with highly irradiated fuel of relatively high ${ }^{235} \mathrm{U}$ enrichment was first attempted in the spring of 1974; at this time major problems were encountered in adjustment of neptunium and plutonium valences, resulting in incomplete recovery of neptunium and poor rejection of plutonium. The studies reported here were undertaken to resolve these problems and enable efficient operation with the modified process.

The first solvent extraction cycles of the original ${ }^{1}$ and modified enriched uranium flowsheets are shown in Figure 1; subsequent processing is identical for the two flowsheets. Major differences in the two flowsheets are:

1. The use of 7.5 vol $\%$ tri-n-butyl phosphate (TBP) in normal paraffin as extractant in the modified process, in place of 3.5 vol \% TBP in the original flowsheet.

2. Use of a scrub stream of $4 \mathrm{M} \mathrm{HNO}_{3}$ in the modified flowsheet, in place of a solution of $1.2 \mathrm{M} \mathrm{Al}\left(\mathrm{NO}_{3}\right)_{3}$ used in the original process.

Valences of plutonium and neptunium are adjusted in both processes by addition of ferrous sulfamate to the feed (1AF) to the first solvent extraction (1A) bank and to the scrub stream (IAS). This reagent reduces neptunium to extractable $\mathrm{Np}^{4+}$ and plutonium to inextractable $\mathrm{Pu}^{3+}$, thereby facilitating their separation in the $1 \mathrm{~A}$ bank.

Process difficulties were first encountered with feed solutions prepared from a mixture of SRP fuels and High Flux Isotope Reactor (HFIR) fuel from Oak Ridge National Laboratory. These highly radioactive solutions contained fission product activities sufficient to irradiate the feed solution to about $300,000 \mathrm{rad} / \mathrm{hr}$. Although similar solutions had been processed without difficulty in the past, using the original flowsheet, neptunium and plutonium behaved anomalously with the modified flowsheet. Rejection of neptunium to the aqueous waste stream (1AW) ranged from $5 \%$ to $75 \%$, while more than $90 \%$ of plutonium present was extracted, 
rather than rejected, in the first cycle. These problems caused a shutdown of the process and the initiation of 1aboratory studies of valence adjustment under the conditions used.

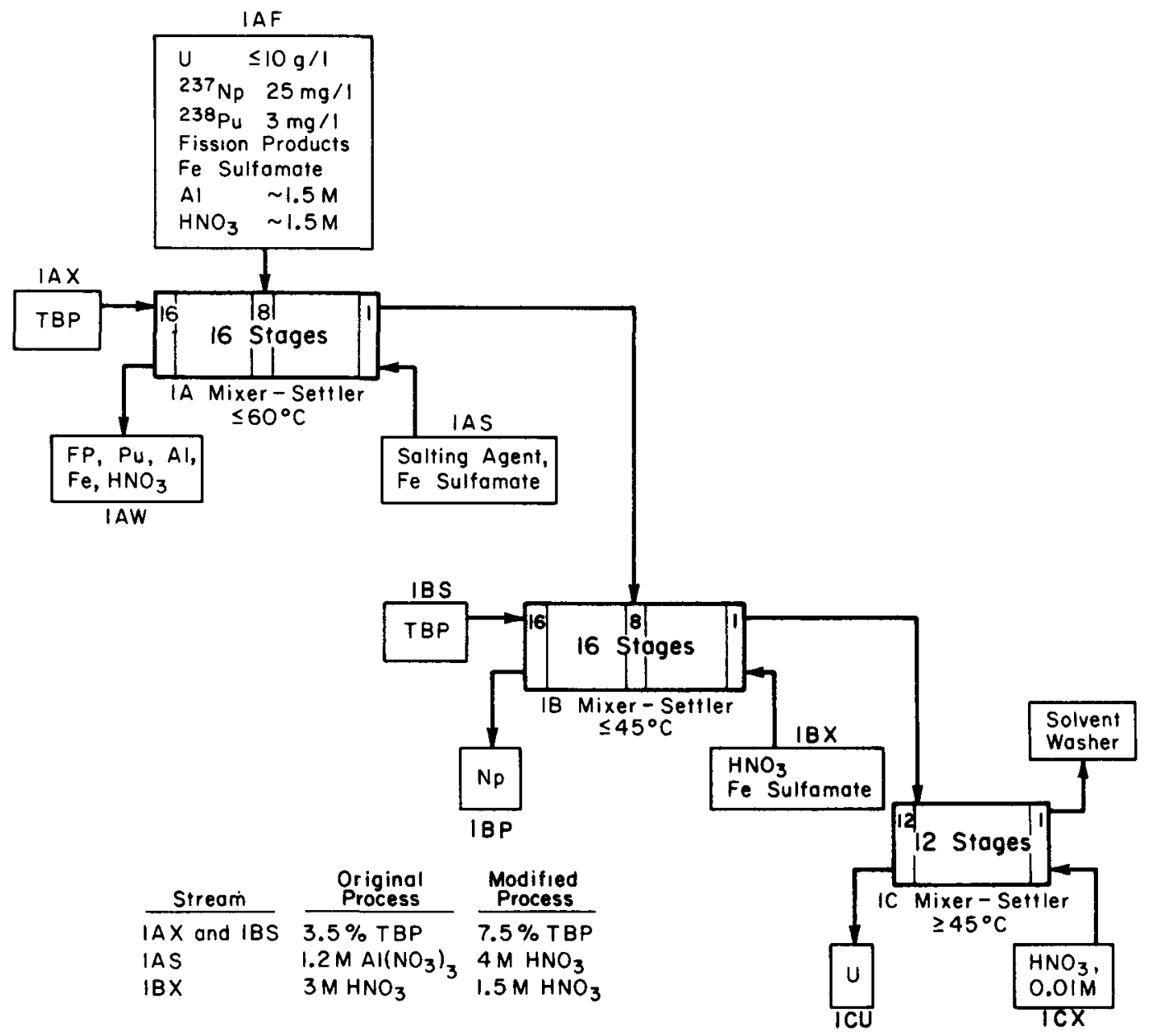

FIGURE 1. Flowsheet for Processing Enriched Uranium

\section{EXPERIMENTAL STUDIES}

Experimental studies of neptunium and plutonium valence adjustment were of three types: (1) tests of process solutions, chemicals, and reagents used in plant operation; (2) studies of the effectiveness of ferrous sulfamate (FeSA) as a reductant and its behavior under process conditions; and (3) solvent extraction tests in the miniature mixer-settler facilities. Each of these is discussed in turn below. Additional details of experimental and analytical methods are given in the Appendix. 


\section{Tests of Solutions and Reagents}

Solvent extraction feed solutions and process reagents were analyzed extensively to determine whether any unexpected impurity was interfering with the process. No such material was found.

Uranium-bearing solutions taken at various stages of processing from the dissolver to the solvent extraction feed tank were analyzed and additionally characterized by spark source mass spectrometry and by titration with potassium permanganate and ferrous sulfamate. The analyses are summarized in Table 1. The only unexpected result was high (nearly quantitative) carryover of manganese from head end treatment into solvent extraction feed. Head end treatment consists of precipitating $\mathrm{MnO}_{2}$ and adding gelatin into the solution to sorb $\mathrm{Zr}$ and $\mathrm{Nb}$ and coagulate silica. As indicated in the table, ferrous sulfamate reduced plutonium and neptunium as expected. In these tests, $\mathrm{Pu}^{4+}$ and $\mathrm{Np}^{4+}$ were analyzed by extraction into thenoyltrifluoroacetone (TTA) solution, followed by gross alpha and alpha pulse height analyses.

Process reagents, namely $\mathrm{HNO}_{3}, \mathrm{Hg}\left(\mathrm{NO}_{3}\right)_{2}, \mathrm{KMnO}_{4}, \mathrm{Fe}\left(\mathrm{NH}_{2} \mathrm{SO}_{3}\right)_{2}$, and gelatin, were evaluated in cold chemical tests using plant chemicals and unirradiated fuel. These analyses revealed nothing in the process solutions or reagents to cause difficulties in solvent extraction.

TABLE 1

Anaiyses of Process Solutions

\begin{tabular}{|c|c|c|c|c|c|}
\hline Solutzon ${ }^{a}$ & $M n, M$ & $\mathrm{NO}_{2}^{-}, \mathrm{M}$ & $\mathrm{Fe}, \mathrm{M}$ & $\begin{array}{l}\mathrm{Pu}^{4+} \text { after } \\
0.02 M \text { FeSA, } \\
\% \text { of total Pu }\end{array}$ & $\begin{array}{l}\text { Extractable } \mathrm{Np} \\
\text { after } 0.02 \mathrm{M} \text { FeSA, } \\
\% \text { of total Np }\end{array}$ \\
\hline $\begin{array}{l}\text { Short-cooled Fuel } \\
\text { Dissolver Solution }\end{array}$ & $8 \times 10^{-6}$ & $c$ & $2 \times 10^{-3}$ & 1 & c \\
\hline $\begin{array}{l}\text { Long-cooled Fuel } \\
\text { Dissolver Solution }\end{array}$ & $4 \times 10^{-5}$ & $c$ & $1.5 \times 10^{-3}$ & 1 & $c$ \\
\hline $\begin{array}{l}\text { Short-cooled Solution } \\
\text { Accountability Tank }\end{array}$ & $1 \times 10^{-4}$ & $c$ & $2 \times 10^{-3}$ & 0.5 & $c$ \\
\hline $\begin{array}{l}\text { Concentrated Blend } \\
\text { before Head End }\end{array}$ & $1 \times 10^{-4}$ & 0.002 & $2 \times 10^{-3}$ & 0.45 & 99 \\
\hline Blend after Head End & 0.018 & 0.004 & $c$ & c & $81-99$ \\
\hline Feed for Solvent Extraction & 0.018 & 0.005 & $0.04^{d}$ & $c$ & 71 \\
\hline
\end{tabular}

a. Short-cooled fuel is cooled 175-200 days before dissolution. Long-cooled fue 1 is cooled $>270$ days before dissolution.

b. Extractions made withın 30 minutes of FeSA addition.

c. Not analyzed

d. Iron $1 \mathrm{~s}$ from FeSA added during feed adjustment. 
Ferrous Sulfamate Stability

\section{Solvent Extraction Feed Solutions}

The stability of ferrous sulfamate reductant in feed (1AF) to the first cycle of solvent extraction was studied by an electrochemical method. The potential between a platinum electrode and either a calomel or a combination glass reference electrode is principally determined by the ferrous-ferric ratio although other solutes (nitrate, nitrite, manganese, mercury, etc.) have some effect. The effect of $0.02 \mathrm{M}$ ferrous sulfamate on the electrochemical potential of several uranium feed solutions was determined (Figure 2), and the potential of the resulting solutions was measured as a function of storage time.

In each case studied the potential rose to a value indicating virtually complete oxidation of ferrous ion within 24 hours; at concentrations of feed containing levels of radioactivity typical of plant operation the oxidation was complete within 6 hours. The interval between addition of ferrous sulfamate to plant feed and solvent extraction of the resulting solution normally exceeds eight hours, so that for solutions containing normal levels of radioactivity, addition of ferrous sulfamate to the feed is ineffective for reducing neptunium and plutonium. It was concluded that all reduction is accomplished by ferrous sulfamate entering the bank in the lAS

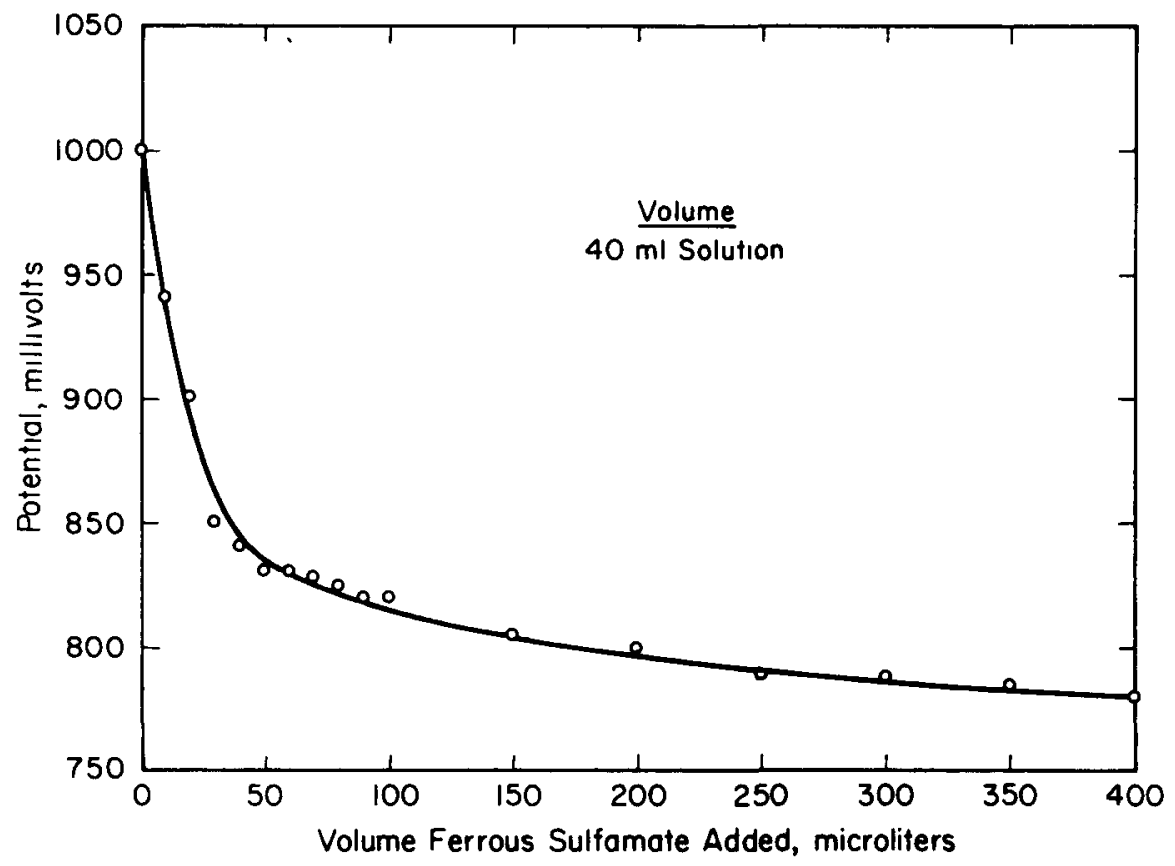

FIGURE 2. Electrochemical Potential as a Function of Added Ferrous Sulfamate (0.02M) in Solvent Extraction Feed 
stream. This conclusion, which is independent of whether the original or the modified flowsheet is being used, is in direct contradiction to conclusions of an earlier study. ${ }^{1}$ In fact, the addition of ferrous sulfamate to the feed inhibits reduction because of the effect of ferric ion thus formed on the ferrous/ ferric ratio in the mixer-settler bank. The potential of the solution is given by the expression

$$
E=E^{\circ} F e^{-\frac{R T}{F}} \ln \frac{\left[\mathrm{Fe}^{2+}\right]}{\left[\mathrm{Fe}^{3+}\right]}
$$

where $E^{\circ}$ is the standard potential for the ferrous-ferric couple, $\mathrm{R}$ is the gas constant, $\mathrm{T}$ is temperature, $\mathrm{F}$ is the Faraday constant, and the bracketed terms are ionic activities. The accumulation of ferric ion shifts the potential toward oxidation and decreases the effectiveness of added ferrous ion for reducing neptunium and plutonium.

A correlation of redox potential with the $\mathrm{Np}^{4^{+}}$and $\mathrm{Pu}^{4^{+}}$ contents in a dissolver solution that had been adjusted to $0.02 \mathrm{M}$ ferrous sulfamate is shown in Figure 3 . After ferrous sulfamate addition, the fractions of $\mathrm{Np}^{4+}$ and $\mathrm{Pu}^{4+}$ and the redox potential were determined as a function of time. Oxidation of neptunium and plutonium was concurrent with the rise in redox potential.

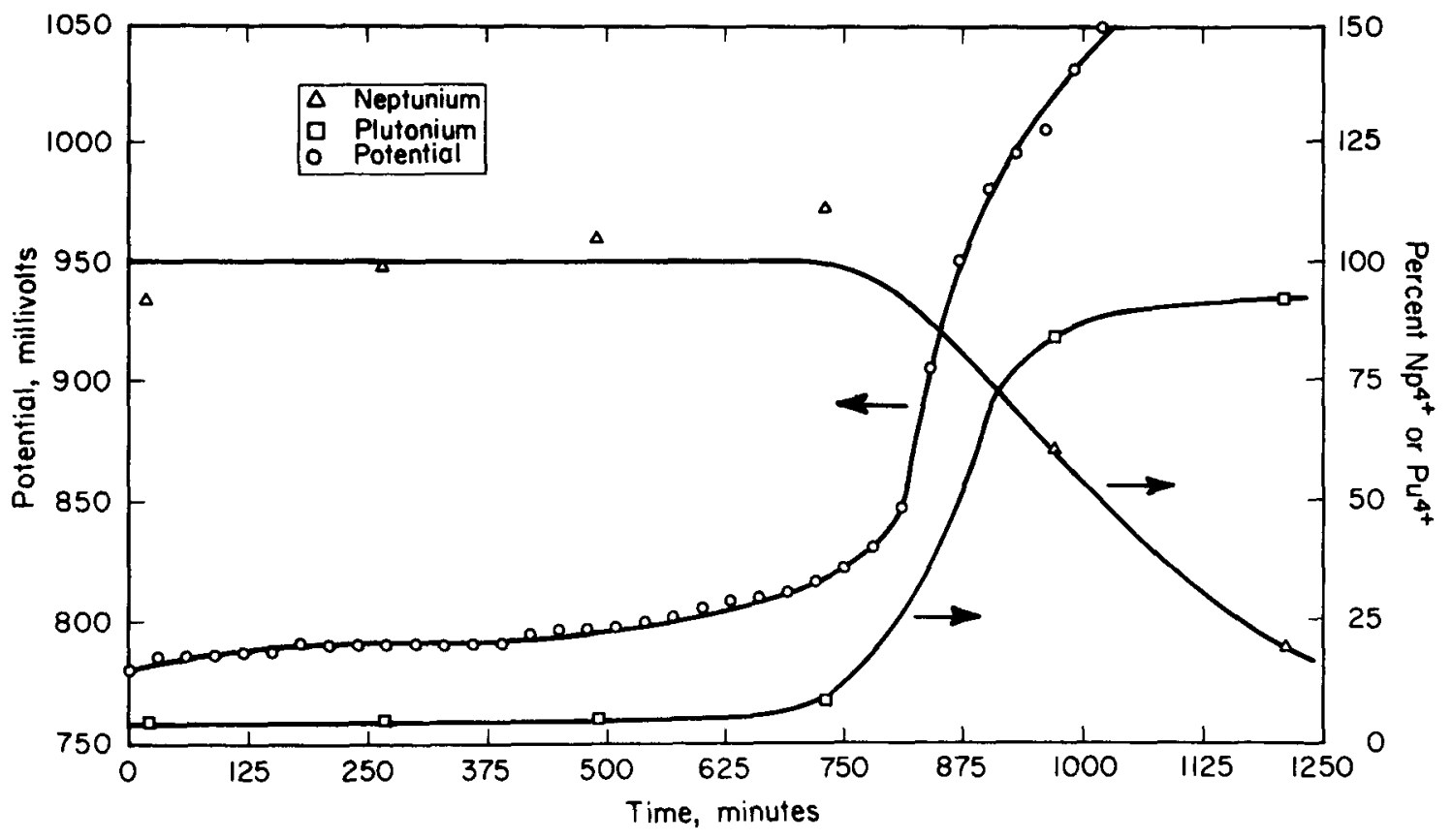

FIGURE 3. Potential, $\mathrm{Np}^{4+}$, and $\mathrm{Pu}^{4+}$ as a Function of Time after Addition of $0.02 \mathrm{M}$ Ferrous Sulfamate in Short-Cooled Dissolver Solution 
Thus, a potential in this system of $800 \mathrm{mV}$ or below indicates a reducing system in which plutonium is present as $\mathrm{Pu}^{3+}$ and neptumium as $\mathrm{Np}^{4+}$. Measurement of the ferrous ion concentration and the ferrous/ferric ratio at 13 and 17 hours after ferrous sulfamate addition gave $3 \times 10^{-3} \mathrm{M}$ ferrous, $0.18 \mathrm{Fe}^{2+} / \mathrm{Fe}^{3+}$ and $7 \times 10^{-4} \mathrm{M}$ ferrous, $0.04 \mathrm{Fe}^{2+} / \mathrm{Fe}^{3+}$, respectively. Correlation of ferrous/ferric analyses, Figure 3, shows that at ferrous/ferric ratios of 0.18 or less, neptunium losses will increase, and more plutonium will be recovered in the uranium product stream.

Radiolytic oxidation of ferrous ion in enriched uranium feed solutions has been confirmed by Bibler ${ }^{2}$, who showed that ferrous ion is rapidly oxidized by $\mathrm{OH}$ radicals, peroxide, and other radiolytically produced species. Sulfamate destruction is slower and sulfamate is ineffective in preventing ferrous oxidation under these conditions.

\section{Scrub Stream}

Since valence adjustment of the feed is (and always has been) ineffective in maintaining reducing conditions during extraction, by either the $3.5 \%$ or the $7.5 \%$ TBP flowsheet, it was concluded that the problem with the $7.5 \%$ TBP flowsheet resulted from oxidation of ferrous ion added in the scrub stream. The scrub stream in the $7.5 \%$ TBP flowsheet is a solution of $4 \mathrm{M}$ nitric acid; in the $3.5 \%$ TBP flowsheet it was $1.2 \mathrm{M} \mathrm{Al}\left(\mathrm{NO}_{3}\right)_{3}$. A review of available data indicated that ferrous ion is oxidized by nitric acid in ferrous sulfamate solutions, following the first order relationship

$$
C=C_{0} e^{-k t}
$$

where $C_{0}$ and $C$ are the ferrous ion concentrations at zero time and time $t$, Orespectively, and $k$ is the first order rate constant. ${ }^{3}$

Table 2 lists rate constants for representative solvent extraction solutions measured in simulated solutions and actual SRP reagents along with calculated values interpolated from Reference 3. The data are consistent; the rate of oxidation of ferrous ion is much greater in $4 \mathrm{M} \mathrm{HNO}_{3}$ solution than in $1.2 \mathrm{M} \mathrm{Al}\left(\mathrm{NO}_{3}\right)_{3}$.

Reactions involved in the oxidation of ferrous sulfamate by nitric acid are:

$$
\begin{aligned}
& 2 \mathrm{H}^{+}+\mathrm{HNO}_{3}+2 \mathrm{Fe}^{2+} \rightarrow 2 \mathrm{Fe}^{3+}+\mathrm{HNO}_{2}+\mathrm{H}_{2} \mathrm{O} \\
& \mathrm{HNO}_{2}+\mathrm{HOSO}_{2} \mathrm{NH}_{2} \rightarrow \mathrm{H}_{2} \mathrm{SO}_{4}+\mathrm{N}_{2}+\mathrm{H}_{2} \mathrm{O} \\
& \mathrm{H}^{+}+\mathrm{HNO}_{2}+\mathrm{Fe}^{2+}+\mathrm{Fe}^{3+}+\mathrm{NO}+\mathrm{H}_{2} \mathrm{O} \\
& \mathrm{HNO}_{3}+2 \mathrm{NO}+\mathrm{H}_{2} \mathrm{O} \rightarrow 3 \mathrm{HNO}_{2} \text { (rapid) }
\end{aligned}
$$


Sulfamate ion reacts with nitrite or nitrous acid and thus stabilizes ferrous ion. In low acid concentrations and at low temperatures it is very effective. At higher temperatures and nitrate concentrations, its effect is diminished (see Table 2).

Two miniature mixer-settler tests were made with simulated, non-radioactive feed to test the stability of ferrous sulfamate during solvent extraction in the absence of radiolysis. Table 3 shows the calculated and measured oxidation of ferrous ion for two different scrub solutions under otherwise identical flowsheet conditions. Calculated results were obtained from the firstorder equation (2) using rate constants from Table 2 and measured volumes of the scrub and extraction sections. Calculated and

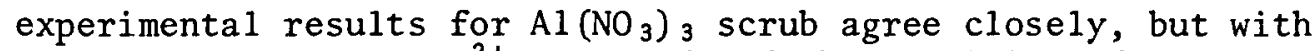
the $\mathrm{HNO}_{3} \mathrm{scrub}$ more $\mathrm{Fe}^{2+}$ was oxidized than anticipated. A review of the experiment showed that this could be attributed to an actual bank temperature $1^{\circ} \mathrm{C}$ to $2^{\circ} \mathrm{C}$ higher than measured, and to the oxidation normally occurring between solution makeup and eventual analysis. The observed ratio $\mathrm{Fe}^{2+} / \mathrm{Fe}^{3+}$ is, however, sufficient to maintain reducing conditions in the extraction section.

TABLE 2

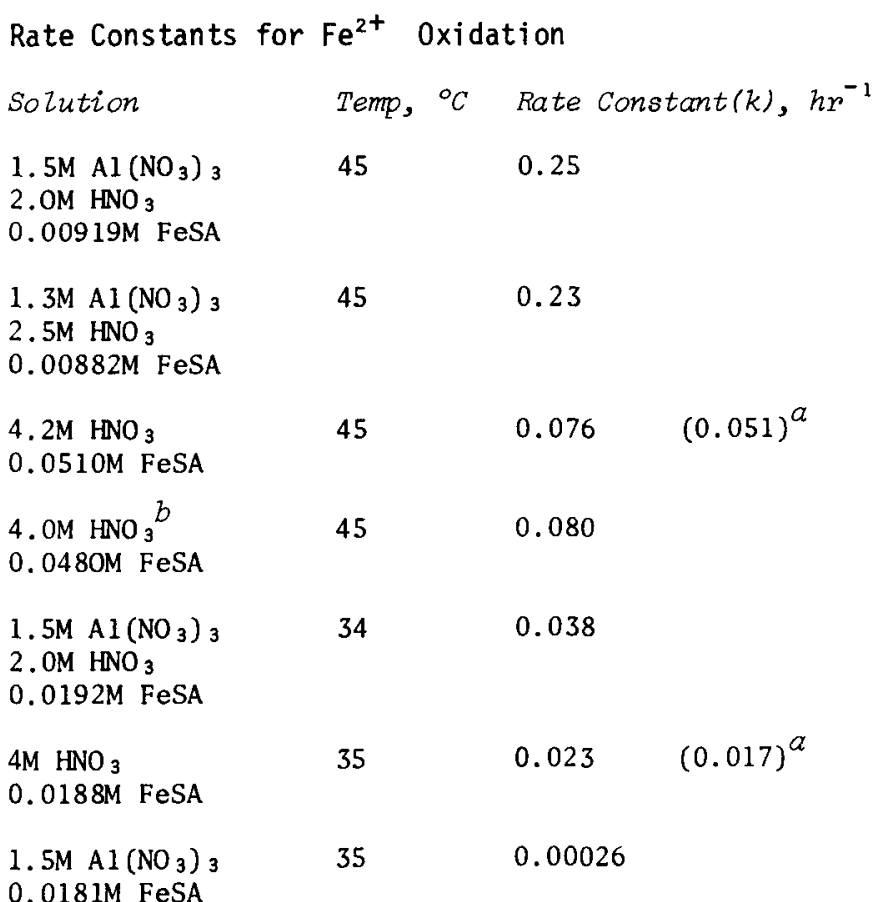

a. Derived from data in Reference 3 .

b. Plant reagent ferrous sulfamate used. 
TABLE 3

Mixer-Settler Tests of Ferrous Sulfamate Stability ${ }^{a}$

Semb

$\frac{\text { Fraction } \mathrm{Fe}^{2+} \text { Remaining }}{\frac{\text { Stage } 9}{\mathrm{k}, \mathrm{hr^{-1b }} \text { Calc. Meas. }} \quad \frac{\text { Stage } 16}{\mathrm{k}, \mathrm{hr^{-1b }} \text { Calc. Meas. }}}$

$0.7 \mathrm{M} \mathrm{Al}\left(\mathrm{NO}_{3}\right)_{3}$

0.001

1.0

1.1

0.10

0.93

0.95

$4 \mathrm{M} \mathrm{HNO}{ }_{3}{ }^{a}$

0.080

0.83

0.67

0.23

0.71

0.60

a. Relative flows $=1 \mathrm{Ar}, 100 ; 1 \mathrm{AX}, 240 ; 1 \mathrm{AS}, 36$; temperature $=45^{\circ} \mathrm{C}$.

b. Rate constants from Table 2.

An additional means for destruction of ferrous ion in the mixer-settler is the reaction with nitrite ion present in the feed from radiolysis (Equation 5). To measure this effect, simulated feed streams with and without nitrite ion were mixed with a $4 \mathrm{M} \mathrm{HNO}_{3}$, $20.035 \mathrm{M}$ ferrous sulfamate solution at $45^{\circ} \mathrm{C}$ in ratios similar to those used in mixer-settler tests. Table 4 shows results of these experiments. The residence time of the solutions in the reaction vessel (10 minutes) was short enough that reaction of ferrous ion with nitric acid was negligible when nitrite was absent. As shown in Table 4, as much as 17 percent of the ferrous ion reacted when nitrite was in the feed. Where low $\mathrm{Fe}^{2+} / \mathrm{Fe}^{3+}$ ratios already exist, oxidation of additional ferrous ion by nitrite ion produced by radiolysis of the feed could destroy the reducing power of the solution.

TABLE 4

Reaction of Nitrite with Ferrous Sulfamate ${ }^{\alpha}$

\begin{tabular}{|c|c|c|c|c|c|c|}
\hline $\begin{array}{l}\mathrm{NO}_{2}^{-}, \\
\text {mmoles/l }\end{array}$ & $\begin{array}{l}\mathrm{Fe}^{2+} \text { in } 4 M \\
\mathrm{HNO}_{3} \text {, } \\
\text { mmoles / }\end{array}$ & $\begin{array}{l}\mathrm{NH}_{2} \mathrm{SO}_{3}^{-} \text {in } \\
4 M \mathrm{HNO}_{3} \text {, } \\
\text { mmole/l }\end{array}$ & $\begin{array}{l}\mathrm{Fe}^{2+} \text { in } \\
\text { Effluent, } \\
\text { mole/l }\end{array}$ & $\begin{array}{l}\mathrm{NH}_{2} \mathrm{SO}_{3}^{-} \text {in } \\
\text { Effluent, } \\
\text { mmole/l }\end{array}$ & $\begin{array}{l}\text { Fraction } \\
F e^{2+} \\
\text { Consumed }\end{array}$ & $\begin{array}{l}\text { Fraction } \\
\mathrm{NH}_{2} \mathrm{SO}_{3} \\
\text { Consumed }\end{array}$ \\
\hline 0 & 36.7 & 78.6 & 9.63 & 20.7 & 0.006 & 0.005 \\
\hline 3.7 & 35.5 & 78.1 & 8.21 & 16.5 & 0.127 & 0.202 \\
\hline 0 & 31.8 & 69.8 & 8.50 & 18.3 & 0 & 0.011 \\
\hline 4.9 & 37.0 & 80.2 & 8.09 & 15.8 & 0.174 & 0.256 \\
\hline
\end{tabular}

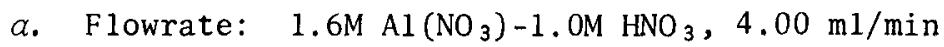
$4 \mathrm{M} \mathrm{HNO}_{3}-\mathrm{Fe}\left(\mathrm{NH}_{2} \mathrm{SO}_{3}\right)_{2}, 1.44 \mathrm{ml} / \mathrm{min}$

Temperature: $45^{\circ} \mathrm{C}$ 


\section{Mixer-Settler Tests}

Eight miniature mixer-settler tests, including seven with actual plant feed solutions, were run to study valence adjustment under actual operating conditions. The tests are summarized in Table 5 .

The first two tests demonstrated the effect of aging the ferrous sulfamate in the feed. With fresh ferrous sulfamate, neptunium recovery was $>99.7 \%$ with a fourth of the plutonium rejected to the aqueous raffinate. Samples taken at 4, 6, and 8 hours (end of test) after startup show $50.5 \%, 50 \%$, and $0.8 \%$ of the plutonium in the aqueous raffinate. Since neptunium was extracted in all cases, this indicates that oxidation of ferrous ion in the feed was affecting only the plutonium. The lack of material balance for plutonium in several tests is principally due to its accumulation in the bank by reflux.

TABLE 5

Miniature Mixer-Settler Tests ${ }^{a}$

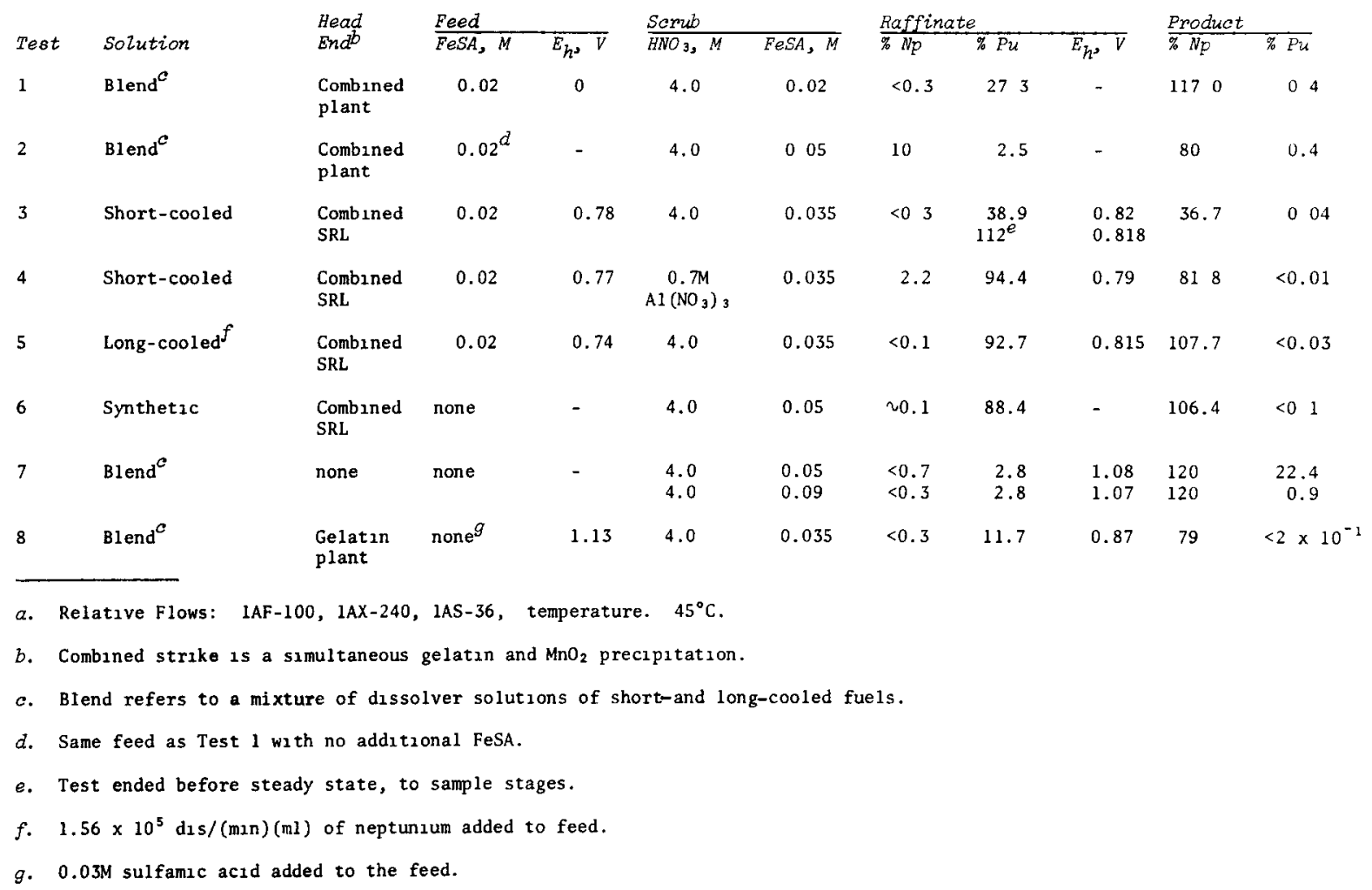


Plutonium reflux is explained as follows: initially enough ferrous ion is present in the feed stage and in stages 9, 10, and probably 11 to reduce both neptunium and plutonium. Neptunium is extracted and carried to the scrub section where fresh ferrous sulfamate from the lAS prevents its reoxidation as it follows the uranium in the organic stream to the $1 \mathrm{~B}$ bank (see Figure 1). $\mathrm{Plutonium}$ is reduced to $\mathrm{Pu}^{{ }^{+}}$and enters the aqueous phase. Initially, enough ferrous ion survives throughout the bank to maintain the reducing potential and hold plutonium in the aqueous phase until it exits the mixer-settler. As radiolysis oxidizes the ferrous ion in the feed to ferric ion, the reducing potential in the extraction section is decreased, so that further oxidation by radiolysis and nitric acid reduces the ferrous/ferric ratio, and some extractable $\mathrm{Pu}^{4+}$ forms. This extracted $\mathrm{Pu}^{4+}$ then follows the organic stream until it encounters reducing conditions and is once again stripped into the aqueous phase as $\mathrm{Pu}^{{ }^{7}}$; thus a plutonium reflux is attained. As the ferrous ion in the feed diminishes, the point of maximum reflux moves from the aqueous raffinate exit stage toward the feed stage. At the end of 8 hours, no ferrous ion is left in the feed, and no plutonium is being rejected to the aqueous raffinate.

Test 2 was run 24 hours later with the same feed but with a higher ferrous sulfamate concentration in the scrub. The data from Tables 3 and 4 indicate a ferrous/ferric ratio in stage 9 of 0.33 . This ratio should suffice to adjust to $\mathrm{Np}^{4+}$ and to $\mathrm{Pu}^{3+}$, but radiolysis and nitric acid oxidation decrease this ratio still further in the extraction section. Nitric acid oxidation alone reduces the ratio to 0.27 in the aqueous raffinate. Again, plutonium reflux occurred, and most, but not all, of the neptunium was recovered in the product. Plutonium losses did not vary with time since there was never any ferrous ion in the feed. The neptunium loss may be partly attributable to the presence of sulfate ion from the decomposition of sulfamate. Sulfate complexes $\mathrm{Np}^{4+}$, limiting neptunium extraction into TBP.

In the next three tests, fresh ferrous sulfamate was present in the feed, and the redox potential was measured in the feed and raffinate. The redox potential in the feed at the start of the test is low enough that neptunium and plutonium are completely reduced. (The feed for Test 5 contained less nitrite than that for Tests 3 and 4 , and since less ferric ion was produced by nitrite reaction, this feed had the lowest potential.) Test 3 represents typical plant conditions of flow rates and concentrations except that the feed solution was freshly prepared; in the plant, at least eight hours elapses between feed makeup and use. Before steady state was attained, the test was stopped to sample stages and characterize any plutonium reflux. The redox potential of the raffinate was low enough that there should have been no 
plutonium reflux; however, the two raffinate samples indicate that some transient reflux had occurred. Stage samples showed plutonium reflux between stages 8 and 16 with a maximum at stage 13 or 14. Neptunium reflux in the scrub section was centered at stage 5 , as expected from the neptunium distribution coefficient in $4 \mathrm{M}$ $\mathrm{HNO}_{3}$. Test 4 used an almost neutral $\mathrm{Al}\left(\mathrm{NO}_{3}\right)_{3}$ scrub solution in which ferrous sulfamate is much more stable to oxidation. Almost all the ferrous sulfamate added in the scrub reached the extraction section and lowered the redox potential of the extraction section and raffinate, so that plutonium and neptunium were effectively reduced.

Test 5 demonstrated successful operation of the nominal flowsheet at a feed radiation level low enough that ferrous ion persists in the feed through the entire test. The long-cooled feed solution used in this test had a gross $\beta+\gamma$ radiation level of about $4.0 \times 10^{10} \mathrm{dis} /(\mathrm{min} \mathrm{ml})$, as compared to $5.0 \times 10^{11}$ $\mathrm{dis} /(\mathrm{min} \mathrm{m} 1)$ for the short-cooled solution in other tests. The redox potential of the raffinate indicated significant oxidation of ferrous ion was still occurring, presumably from nitric acid in the scrub stream.

To demonstrate further that ferrous sulfamate is required only in the scrub, test 6 was made with synthetic feed containing $20.8 \mathrm{mg} / \mathrm{ml}$ neptunium and no ferrous sulfamate. Excellent separation of neptunium and plutonium was attained. Analyses of raffinate samples within 24 hours showed a relatively constant ferrous/ferric ratio of about 0.3 . Using Equation 1 and $\mathrm{E}^{\circ}=0.771,{ }^{4}$ the redox potential of the raffinate is $\sim 0.80$ volts. This agrees with the previous tests in which neptunium and plutonium were reduced at potentials under 0.82 volts.

The last two tests were with plant feed solutions and with ferrous sulfamate only in the scrub. Test 7 resulted in extraction of both neptunium and plutonium. The reason for plutonium extraction is unknown. Ferrous sulfamate in the scrub was stable with less than $5 \%$ oxidation between solution makeup and the end of the test. Even increasing the ferrous concentration from $0.05 \mathrm{M}$ to $0.09 \mathrm{M}$ did not reduce the raffinate potential significantly or prevent plutonium reflux.

The unusual results observed in Test 7 were not readily understood; however, it is possible that some species in the feed catalyzed the oxidation of ferrous ion. The feed had no treatment other than concentration by evaporation prior to use as solvent extraction feed. Test 8 , in which the feed had been subjected to a gelatin strike in the plant and later adjusted to $0.03 \mathrm{M}$ sulfamic acid to remove nitrite ion formed from radiolysis, gave better results with lower ferrous sulfamate in the scrub. Plutonium reflux 
and a high potential in the aqueous raffinate were also noted in this test, indicating that more ferrous sulfamate is needed in the scrub.

Studies of head-end precipitations were made in conjunction with these tests to account for the high carryover of manganese into the feed that was observed in plant solutions.

In Tests 3, 4, and 5 combined $\mathrm{MnO}_{2}$-gelatin precipitations were included to simulate plant operations for ${ }^{95} \mathrm{Zr}-{ }^{95} \mathrm{Nb}$ removal. Precipitates formed were finely divided, settled slowly, and filtered inefficiently. The filtrates when analyzed contained about the same concentration of manganese as observed in plant solutions (see Table 1). More extensive investigations of the problem demonstrated that the high concentration of $\mathrm{Al}\left(\mathrm{NO}_{3}\right)_{3}$ caused small particle formation and slow settling of $\mathrm{MnO}_{2}$ precipitates with subsequent carryover of fines even after centrifugation. 5 This had probably occurred frequently in past operations, but was not noticed. The fines are then dissolved by radiolysis, the products of radiolysis $\left(\mathrm{NO}_{2}^{-}\right)$, or addition of reducing agent. 5

\section{APPLICATION TO PLANT PROCESSING}

As a result of these studies the plant process was modified so that the IAS stream was prepared by mixing separate nitric acid and ferrous sulfamate streams just before they were fed to the mixer-settler. Efficient ( $>98 \%$ ) recovery of neptunium and $>99 \%$ rejection of plutonium was obtained in this manner. Subsequently, ferrous sulfamate was eliminated from feed solutions, and as anticipated from the laboratory studies, no effect on the partitioning process was observed. 


\section{APPENDIX}

\section{Experimental Methods}

Reagents

Reagent-grade nitric acid and aluminum nitrate were used in preparing simulated solutions and scrub solutions. Plant reagents, (40wt $\%$ ferrous sulfamate, 6 wt $\% \mathrm{KMnO}_{4}$, and gelatin) were used in miniature mixer-settler tests. Ferrous sulfamate for use in analyses and stability studies was made by dissolving reagent grade iron filings in sulfamic acid solution to give a $2 \mathrm{M}$ stock solution of ferrous sulfamate.

\section{Analytical Methods}

Plutonium and neptunium were determined by gross alpha and alpha pulse height analyses after separation by thenoyltrifluoroacetone (TTA) extraction using ferrous sulfamate for valence adjustments. $\mathrm{Pu}^{4+}$ and $\mathrm{Np}^{4+}$ were analyzed by direct extraction into TTA and back extraction into nitric acid before separation and counting.

Manganese and ferrous/ferric ratios were determined by scanning coulometry.

Redox potentials were measured with a $\mathrm{pH}$ meter used in the millivolt mode, a platinum electrode, and a calomel or $\mathrm{Ag} \mid \mathrm{AgCl}$ reference electrode. The redox potential is obtained by first measuring the millivolt potential in a stirred sample of $\mathrm{ZoBell}$ solution ${ }^{6}$ where

$$
\mathrm{E}_{\mathrm{o}}=430 \text { - potential reading in } \mathrm{mV}
$$

The redox potential of the sample relative to the Normal Hydrogen Electrode, $E_{h}$, is obtained from $E_{0}$ and the measured potential of a stirred sample solution.

$$
E_{h}=E_{0}+\text { potential reading of sample in } m V
$$

Rate constants for oxidation of ferrous sulfamate by nitric acid and aluminum nitrate solutions were obtained by placing an aliquot of $2 \mathrm{M}$ ferrous sulfamate in the desired solution in a constant temperature bath. Samples of the solution were taken periodically for ferrous and sulfamate analyses. The $\log$ of 
ferrous ion concentration was plotted versus time and the slope of the straight line obtained is the reaction rate constant shown in Table 2 .

Ferrous ion was determined by titration with ceric ion using ferrous tris-o-phenanthroline indicator. Sulfamate ion was determined by reaction with excess nitrite, oxidation of excess nitrite with excess ceric ion, and back titration of excess ceric with ferrous ammonium sulfate in dilute sulfuric acid. 


\section{ACKNOWLEDGEMENTS}

The authors wish to thank R. M. Wallace for some of the work on ferrous sulfamate stability in nitric acid; also E. W. Baumann for developing and testing the method for measuring redox potentials.

\section{REFERENCES}

1. H. J. Groh and C. S. Schlea. "Recovery of Neptunium-237 and Plutonium-238." pp 517-522 in Progress in Nuclear Energy. Series III. Process Chemistry Vol. 4, C. E. Stevenson, E. A. Mason, and A. T. Gresky, Eds., Pergamon Press, London (1970).

2. N. E. Bibler. "Radiolytic Instability of Ferrous Sulfamate in Nuclear Process Solutions." Radiation Effects, to be published.

3. E. K. Dukes and R. M. Wallace. Stability of Ferrous Sulfamate in Nitric Acid Solutions. USAEC Report DP-871, E. I. du Pont de Nemours and Company, Savannah River Laboratory, Aiken, SC (1964).

4. Louis Meites, Ed. Hondbook of Analytical Chemistry. pp 5-7, McGraw-Hill, New York (1963).

5. H. D. Harmon. The Decontamination of Dissolved U-AZ Fuel by Simultaneous Treatment with Gelatin and $\mathrm{MnO}_{2}$. USERDA Report DP-1376, E. I. du Pont de Nemours and Company, Savannah River Laboratory, Aiken, SC (1975).

6. C. E. ZoBel1. "Oxidation-Reduction of Marine Sediments." Buzz. Am. Assoc. Petroleum Geol. 30, 477 (1946). 


\section{DISTRIBUTION}

\section{Copy}

1-3 T. B. Niland, ERDA-SR

4-44 TIS File, SRL

45-154 ERDA-TIC

(for distribution under TID-4500 Category UC-10) 